\title{
ENHANCING LEARNING OUTCOMES BY INTRODUCING BIM IN CIVIL ENGINEERING STUDIES - EXPERIENCES FROM A UNIVERSITY COLLEGE IN NORWAY
}

\author{
ANN KARINA LASSEN, EILIF HJELSETH \& TOR TOLLNES \\ Oslo and Akershus University College of Applied Sciences, Norway
}

\begin{abstract}
It is a challenge to introduce building information modeling (BIM), as demanded from the industry, in an already packed curriculum for higher engineering education. There is therefore a need for alternative ways to include BIM in the curriculum, while at the same time strengthening - rather than supplanting the traditional engineering subjects. The purpose of this study is increased understanding of how BIM can be integrated as part of an engineering curriculum in an efficient way. The study is based on an evaluation of the 'Introduction to Building Professions' course given to all civil engineering students in their first semester of the bachelor's degree programme at Oslo and Akershus University College of Applied Sciences in Norway. Autodesk Revit was used as BIM-based software in the designing of a two-family timber dwelling, a compulsory group project in the course. Data for this paper are collected from multiple sources: a net-based questionnaire, course evaluations, interviews with students and teachers, and assessment of students' project work. Selected factors in Active Learning theories are used as a theoretical lens for analyzing the data in a systematic way. BIM enabled a design and 'virtual construction' process where students held professional roles in a design team, and contributed with their expertise toward a holistic solution. The students reported that the hands-on modeling with BIMbased software led to increased understanding of design parameters, load distribution, and construction detailing, as well as information requirements for collaboration within a design team. We conclude that BIM in higher engineering education can support understanding of professional content, which is the primary learning outcome. Software proficiency is seen as a necessary yet subordinate skill in higher education and should not be graded as a separate task. Use of BIM-based software should, however, be integrated to enhance problem understanding and relevant information processing. This integrated approach can lead to a more widespread implementation of BIM to support active learning in higher education.

Keywords: active learning; BIM; civil engineering; higher education; project-based learning.
\end{abstract}

\section{INTRODUCTION}

Adoption of building information modeling (BIM) has surged in the architecture, engineering, and construction (AEC) industry [1]. Many established practitioners struggle to keep up with the development, and there is a need for educated users. Much of the responsibility to provide this will fall on institutions of higher learning [2].

In many ways, the skills required to be a competent user of BIM are not of an academic nature. Education in BIM is normally offered at trade schools and vocational colleges. Nevertheless, proficiency in BIM has become a necessity for all actors in the building construction chain, including architects and consultant engineers. Just as a managing director will master word processing and spreadsheets, a design professional will work hands-on with modeling. Many institutions of higher learning have looked at ways to add these skills to their curriculum [3]. In addition to applying 3-D modeling for design and representation, some teach students about collaborative working through the use of BIM [4].

Active learning is a well-established educational method, covering, amongst other techniques, student activating and interactive lectures [5], experiential learning [6], collaborative learning [7], and project-based learning [8]. Bruner and others have pointed out that 
discovery leads to learning [9]. Ever since Confucius' day, we hear that doing is learning, but also that seeing is remembering. Visualizing is one of three learning modalities, alongside listening (auditory) and doing (kinesthetic) [10]. Such pedagogical methods have been found by Biggs and others to lead to deep learning and greater understanding of concepts $[11,12]$. Intrinsic motivation is primarily due to personal interest, enjoyment and inherent satisfaction, and according to Ryan and Deci's Self Determination Theory, this can only be maintained through a sense of competence, autonomy, and relatedness [13]. When one feels competent, in charge and appreciated, the natural motivation from within can flourish. Deci, Koestner and Ryan go so far as to claim that external factors, such as grades, can be detrimental to this intrinsic motivation [14]. It must be added, however, that students have been found to prefer being evaluated through exams, and being judged on their individual work rather than group work [15].

Modeling in BIM might be a useful way to both activate and motivate students. However, a fresh student of civil engineering has a great deal of new concepts to master - statics, building physics with resultant building skin construction, material use, heating and ventilation, and sustainable energy design, to name some. It can be a challenge to fit BIM classes into an already packed curriculum without supplanting other important learning goals. Ideally, one should look for alternative ways to include BIM, while at the same time strengthening rather than supplanting - the traditional engineering subjects. We propose that an integrated approach would be the efficient way to go.

Speaking at the BIM Academic Forum UK workshop in 2013, Aled Williams proposed that in a teaching situation at a higher education institution with fully imbedded BIM, 'BIM is so important it should become the 'vehicle' for our students' learning experience. Teaching should (sic.) enabled by the BIM model' [16]. This thinking coincides with how we at Oslo and Akershus University College of Applied Sciences have applied BIM in the 'Introduction to Building Professions' course given to all civil engineering students in their first semester of the bachelor's degree program. The didactic advantages that we hope to gain by integrating BIM within the constraints of a 10 ECTS course in basic building technology are listed in Table 1.

These are ambitious goals for a first-semester course, and they deserve an evaluation. The findings in this case study are organized after the above four elements. The research question is to explore 'How has integrating BIM in an engineering curriculum enhanced learning outcomes?' Positive outcome can result in a more efficient way to enhance advanced learning outcomes while simultaneously teaching sought-after practical skills.

\section{PRESENTATION OF THE BIM CASE}

The two undergraduate engineering study programs of Civil and Structural Engineering and Energy and Indoor Environment in Buildings take a joint introductory course named 'Introduction to Building Professions' in the first semester. The course, which carries 10

Table 1: Didactic goals of integrating BIM in an engineering curriculum.

1 BIM and modeling skills for design and representation

2 Applying BIM for collaborative working

3 Active learning and visualization for deep learning and understanding of buildings

4 Sense of autonomy, competence, and relatedness for intrinsic motivation 
ECTS, is to familiarize the students with engineers' practices within the building industry, with a focus on collaboration and oral, written and visual (3D) communication. The students acquire knowledge of and develop skills in designing technological solutions for timber houses. There were 212 students in the autumn of 2016, organized into 40 teams.

From the start of the semester, parallel with introductory lectures on load-bearing structures, building physics, indoor climate design, etc., the students have six practical 2-h lessons in the use of Revit. The students also start on the sketch phase of their group project - designing a two-family timber dwelling. For this, each member of every group takes a role in the design team: client's planning manager, architect, consultant engineers (construction and HVAC) and contractor. After completion of the Revit lessons, the teams model their designs in 3-D, worksharing on the same file.

Modeling the load-bearing constructions, specifying outer walls and roof to fulfill U-value requirements, and positioning ducts for the ventilation system are amongst the tasks to be completed. The different professions in the team need to collaborate and check for clashes in the model. This is carried out manually in Revit and does not, as such, take full advantage of BIM's interoperability, yet the opportunities for coordinating the various contributions becomes evident. Figure 1 shows illustrations from a typical project that students have modeled in Revit.

The intended learning outcomes stated in the course description include knowledge about building physics, structures and detailing, and communication needs; skills in collaboration, planning, design, and presenting results through BIM-based tools; and competence in collaborating and communicating with related professions. The Revit lessons are mandatory, as is completion of the group project. They are summatively assessed as 'pass' or 'fail'. Even though the project is only assessed 'pass' or 'fail', we observe that students put in a great amount of effort in their work. At various stages of the process, the projects receive feedback from teachers and are peer evaluated and critiqued in plenary sessions. The final graded assessment of the course as a whole is done in the form of a written exam.

\section{METHOD}

This case study is based on data collected from a net-based questionnaire and a course evaluation. All 212 students in the course received an e-mail with instructions on how to participate in the netbased survey, shortly after they had finalized the course and while they were preparing for their exams. We received 62 answers, or 30\% feedback, on this survey, which had both closed and open questions about BIM and Revit in the course. The course evaluation was a standard evaluation by students about the course in general. This was carried out mid-term as a 5-min open form where the students expressed what they found positive and negative about the lectures, Revit-course and
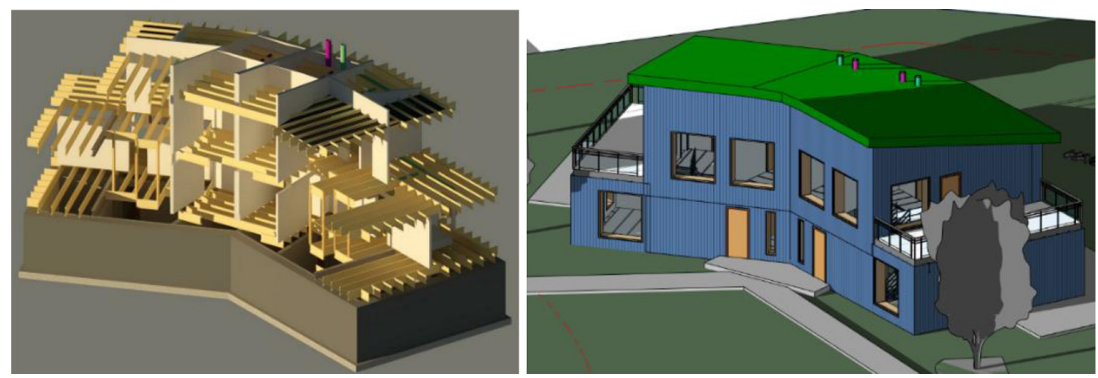

Figure 1: Example of Revit model from a student team in the 2016 course. 
project, respectively. Ninety-seven students responded, giving a 45\% answer rate. Both surveys were conducted anonymously.

The findings are organized according to the four didactic goals presented in Table 1, so as to have a logic structure for the presentation.

\section{FINDINGS}

Sixty-two students responded to the net-based questionnaire. Seventy-two percent had never modeled in 3-D before the course; 5\% had used Revit, 18\% had used SketchUp, and 16.5\% had used another 3-D modeling program. Ten percent found it very hard to learn Revit, while $60 \%$ disagreed to some extent or other. Only $6.5 \%$ thought that it was irrelevant and should be removed from the course.

\subsection{BIM and modeling skills}

For a start, $88.5 \%$ felt that working with Revit in the project anchored their Revit skills. When asked whether they thought there was a need for BIM competency in the industry, $70.5 \%$ agreed. Only $3 \%$ partially disagreed, while $26 \%$ did not know. $85 \%$ agreed that it will be extremely important to have knowledge about methods for the use of Revit and BIM when applying for a job as an engineer (Fig. 2).

We asked the students what they thought were the greatest advantages of learning Revit, and answers included "That we learn this before we hit the job market, where we are sure to need it."; "It gives us from HiOA [acronym for the college] an advantage with regards to getting a job, if we master this."; "We live in a world where computer programs are used more and more, so I see Revit as a step in the right direction."; "This is used in the industry, so it's good to have the experience."

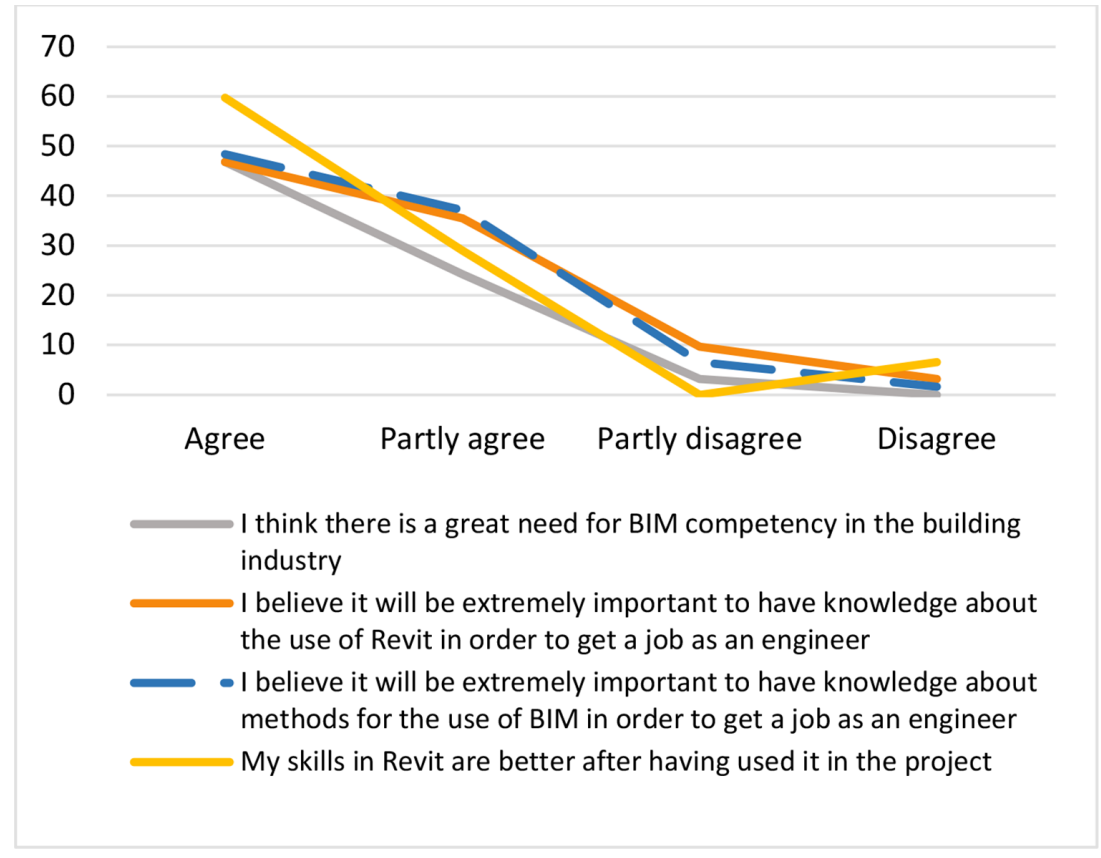

Figure 2: BIM and modeling skills. 
The course evaluation indicated that the lab course was seen as a good way to learn Revit in a short space of time.

\subsection{Collaborative working}

The students overwhelmingly agreed that BIM helped them with collaborating within the team. Eighty percent reported that the members of the team worked together and helped each other with mastering Revit. Seventy-five percent meant that they better understood other professions' roles in the design process by working together in a joint 3-D model.

To the open question stated above regarding advantages, the students showed that they not only saw the advantages within their project, but also the real-life advantages: "You see the value of integrated design"; "Easier to collaborate with other professions"; "Opportunity to collaborate with other professions in the same model and in real time"; "Offers a very good basis for discussing solutions with other professions"; "Collaboration, planning and communication between architect, consulting engineers, contractor and project leader are important factors for building a house." However, one student took the opportunity to comment that "while we were told to follow what everyone in the team is doing and why, in reality that's not happening in many teams."

The comments from the course evaluation show that many students appreciate that the project is of a realistic nature, that they learn something about the entire building process and about collaborating with other professions. Of course, there were also students who struggled within their teams, and some felt that they did not really have an insight into what their mates were immersed in (Fig. 3).

\subsection{Deep learning and understanding of buildings}

Sixty-nine percent felt that working with Revit made it easier to understand how a building is constructed, than if this had solely been taught through lectures. On whether the college

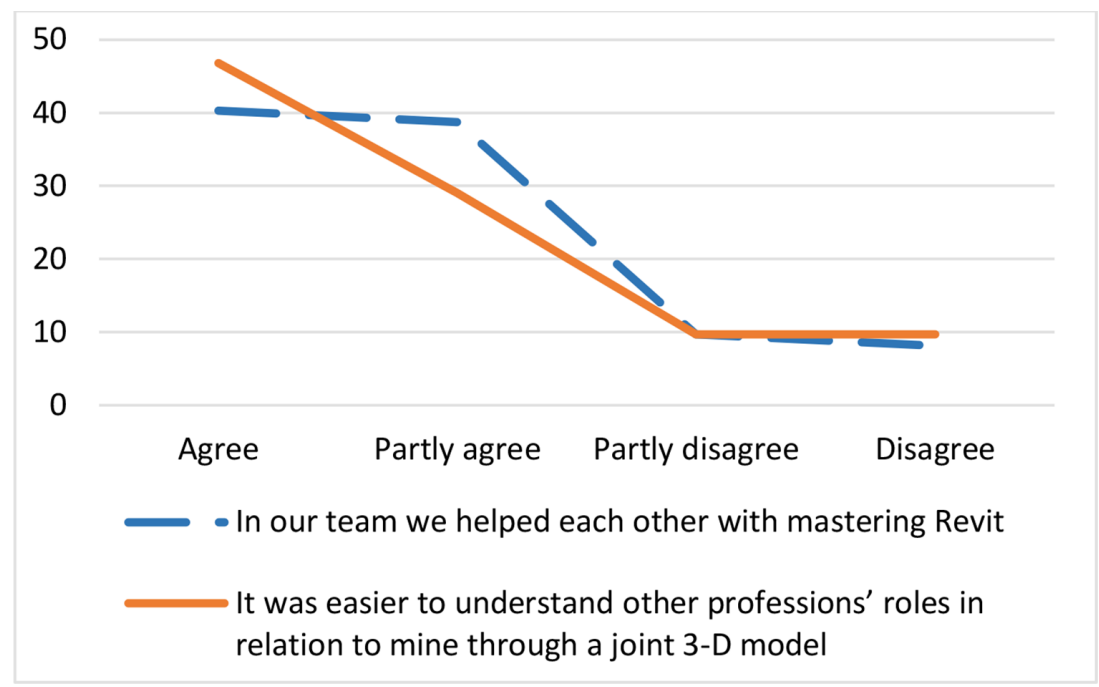

Figure 3: Collaborative working. 
should put more emphasis on Revit and less on traditional engineering topics, such as building construction and environmental design, opinions varied greatly with quite an even distribution. Nevertheless, only $28 \%$ felt that more lectures and less time spent on Revit would have taught them more.

Many answers to the same question regarding advantages emphasize this: "The biggest advantage is that students with no experience with construction drawings can see the overall picture of the structure and so can better understand 2D drawings"; "Useful for seeing how the construction of a wooden house is built up.; "Visualizes solutions well. Easy to see if solutions will work or not"; "Visual understanding of how a building is put together"; "Understanding." As a general comment, it was said: "Revit is interesting and instructional." Nevertheless, one student saw the potential for more: "I think that most students would have had a better learning outcome if the Revit lessons had more clearly explained what we were "building" [modeling] and why it is built like that. [...] It would also be easier to understand building technology if the Revit lessons and building technology lessons had followed each other more closely."

From the course evaluation, we saw that students found it exciting to get to apply newly accessed knowledge from the lectures. Many felt that the project was a good way to learn, and that it was well suited as an introduction to the building professions. On a scale from 1 to 7 , the course as a whole scored an average of 5 when it came to achievement of the learning objectives (Fig. 4).

\subsection{Motivation}

$65.5 \%$ felt that working with Revit would make them a more motivated student, and $72 \%$ reported that Revit had inspired them to learn more about the building professions. As many as $92 \%$ found Revit fun to work with.

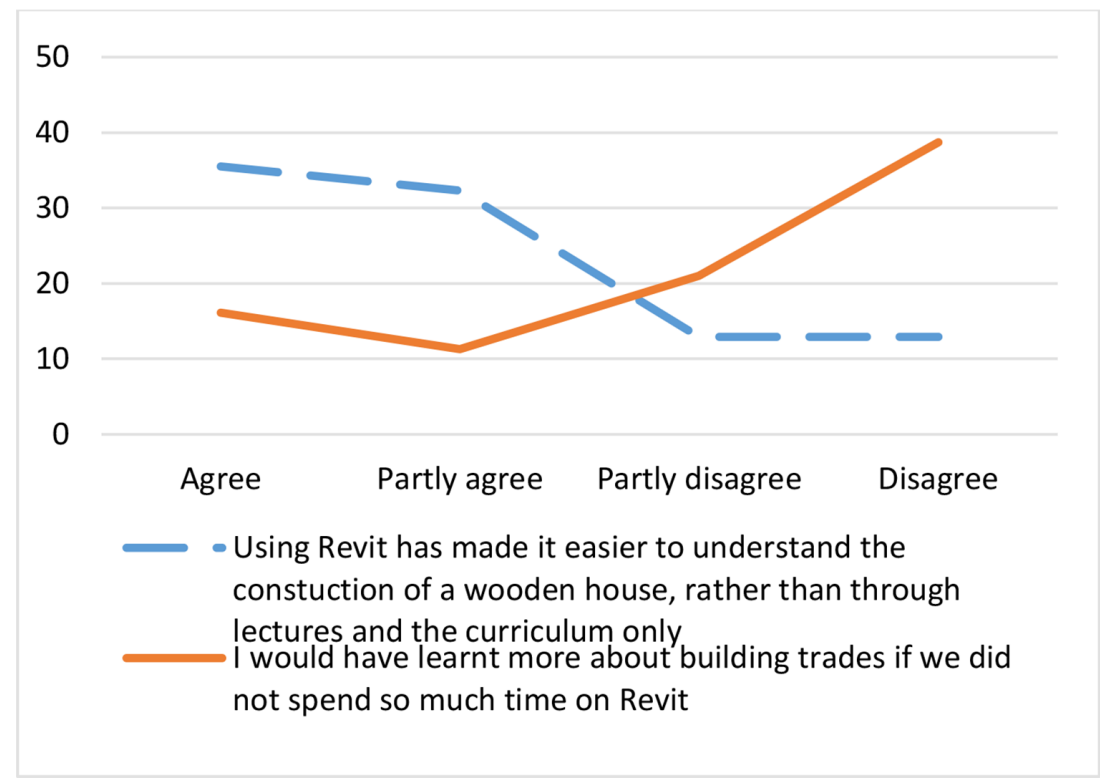

Figure 4: Deep learning and understanding of buildings. 


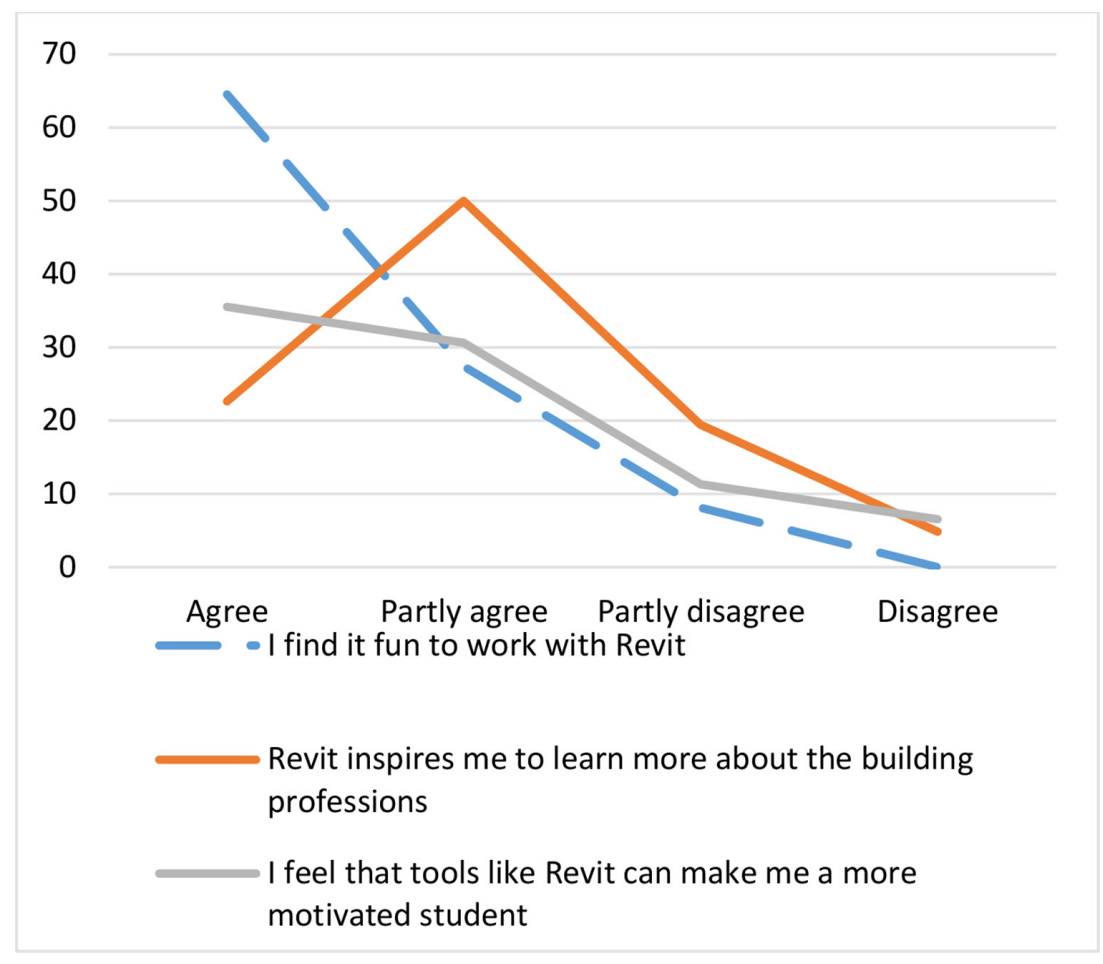

Figure 5: Motivation.

Answers included "I'm satisfied with BIM as a part of the course, and the way it is applied in teaching, with tutoring and then as a tool in the project."; "The Revit education is both relevant, rewarding and inspiring."

The course evaluation also revealed that students found the project fun. The 'learning by doing' and need to manage their own learning was appreciated by many - but not all!

All in all, the students seemed to feel that working with Revit in the project took a great deal of their time. While they appreciated this way of learning within the course, they admitted that it did steal time from other commitments: "Skilled teachers and an interesting subject, but the project takes up much time from other courses." Furthermore, many students were disappointed with the fact that the project is not assessed with grades beyond 'Pass' or 'Fail'. They felt that the hours spent working with Revit should be rewarded with the opportunity to improve their overall grade in the course. Some complained that what they learnt about Revit is not relevant to the exam. The last student quoted above went on to say “... but I feel that the [Revit-]course and the project give very little dividends regarding the exam. Since the project does not generate grades, the time spent seems wasted." Other quotes support this: "It seems meaningless to have spent so much time on Revit when it is not relevant to the exam!"; "What is the point of spending so much time on something which only gives a pass? When it's the grades that matter!"

\section{DISCUSSION}

This case study initially explores how the course "Introduction to Building Professions" succeeds in teaching 3D modeling, BIM collaboration, and in addition, the way buildings are constructed. The results are very much in keeping with active learning theories. The students reinforced 
their mastery of Revit by using their newly obtained skills to model their own design. At the same time, visualization aided their understanding of how a building is constructed, and anchored this learning. Teamwork allowed them to experience the advantages and challenges of collaborative working. Passive learning in the lecture theatre would not have been as effective. As for motivation, we argue that these objectives could only be achieved because the students were highly motivated. Since the lure of good grades was not the motivator, we look to Ryan and Deci's Self Determination Theory for answers, and structure the rest of the discussion according to their three criteria for intrinsic motivation: competence, autonomy, and relatedness. Competence gives a sense of self-confidence and self-esteem [17]. By autonomy, Ryan and Deci mean the sense that one is in control and can make one's own choices [13]. Relatedness has to do with the feeling of belonging and interpersonal connectedness [13].

\subsection{Competence}

The competence gained in the course cover both 3D modeling and technical knowledge of buildings. For both, the results of the survey are totally in keeping with active learning theories. Firstly, the students feel reasonably competent after having finished the Revit course. They reinforced their mastery of Revit by using their newly obtained skills to model their own design. At the same time, visualization aided their understanding of how a building is constructed, and anchored this learning. Passive learning in the lecture theatre would not have been as effective. However, one student did point out that more explanation about just what they were modeling in the Revit course, and why, would be more useful. The Revit teachers usually strive to do this, but if much time is spent in class helping individual students who are struggling with the program, this opportunity is lost. One way to solve this may be to include such text in the compendium, so that the students can access it by self-study.

\subsection{Relatedness}

By having a group project with 5-6 students per group, we ensure that every first-year attains a feeling of belonging from week one. In a large class of more than 200 students this will be of great importance. The students' responses regarding the value of the teamwork confirm this. Having the support of mates, as well as feeling needed and responsible, are basic human needs. Also, having someone to spar with brings out our potential. Developing skills in collaborating through BIM enables the students to feel competent in this relationship. To be sure, some teams struggled internally, but when reminded that this could be seen as an added learning opportunity, they tended to take it on as a challenge. Some students do not enjoy teamwork on a whole - this is in keeping with the findings of Patricia Machemer and Pat Crawford [15] in their study of student perceptions of active learning. Students' perceptions of what they prefer does not necessarily coincide with what research shows is actually best for their overall results, as Machemer and Crawford are the first to admit. Mark Huxham writes: "student evaluations, on their own, do not provide sufficient grounds for changing teaching practice ... what students want may not be what is pedagogically best' [18].

\subsection{Autonomy}

The perception of being at choice is the most important factor for intrinsic motivation. Most can be motivated (at least for a while) without belonging to a group, and we can be motivated 
without having all the necessary skills (though motivation will quickly lead one to gaining competence), but we cannot be motivated without a sense of self-determination [13]. We all have different tastes and interests, and if the task at hand coincides with our perception of what is joyful or fascinating, it will capture our attention. Also, we all enjoy being creative and seeing results when our ideas come to fulfillment. Applying newly learned Revit skills on a design of their own creation was perceived by the students as meaningful and fun. When coming across challenges in their own construction, they were spontaneously motivated to find the solution.

\subsection{Intrinsic vs. extrinsic motivation}

Ryan and Deci describe the impact of intrinsic motivation: "Perhaps no single phenomenon reflects the positive potential of human nature as much as intrinsic motivation, the inherent tendency to seek out novelty and challenges, to extend and exercise one's capacities, to explore, and to learn" [13]. So far, we have been speaking of maintaining that in-born natural drive. Motivation can also come from external factors, such as the threat of punishment, or the promise of rewards. While external consequences tend to be detrimental to intrinsic motivation, this need not always be the case. Extrinsic motivation can be internalized as our own if it makes sense to us. Therefore, if we intrinsically wish to have a meaningful job in the future, acquiring the necessary skills can be a powerful internalized motivation [19]. Not all students are likely to find modeling in Revit intrinsically joyful. However, the task of modeling in Revit was perceived as meaningful, as the great majority of students saw the importance of being skilled in Revit and BIM when applying for a job in the future.

As the comments also showed, there was some disappointment that these skills were not awarded grades. The extrinsic motivation of exams and grades are so internalized that many students feel cheated when they do not receive the reward that grades may represent. This is also in keeping with Machemer and Crawford's findings on students' perceptions of learning [15]. However, we argue again that students' perceptions are not always truths, and that Deci and Ryan are right in their well-researched theory that intrinsic motivation is the most conducive to learning.

The high quality of the project work indicates that the students spend much time on the BIM project. Some students comment that they spend 'too much time'. However, these comments only amplify the understanding that this exercise must be motivating. Since the students know that they will not be rewarded with a grade, they must be spending the extra time because they find it intrinsically rewarding.

This high-impact learning environment with BIM integrated into the practical exercise is just what makes the course so efficient at teaching 3D modeling and BIM collaboration, as well as how buildings are constructed.

\section{IMPLICATIONS}

The results from integrating BIM in an introduction engineering course at HiOA in Norway show that the students are happy with the course and respond with positive feedback, in spite of certain complaints. The students' efforts have been much higher than one might expect, considering that the project has only an indirect transference to the final written individual exam, and the project itself is not graded. The students perceive that they learn more about buildings than if they only attended lectures, and the quality of the project work - both content and BIM execution - shows that the students learn a great deal within the 10 ECTS first 
semester course. Our findings have been analyzed by use of the Self-Determination Theory framework. The learning environment in this course supports autonomy, competence, and relatedness based on the following logic:

- Students working smarter because they are encouraged to develop their skills and expertise (competence)

- Students working more seriously because responsibility is placed in their hands (relatedness)

- Students working dedicatedly because of stronger involvement and commitment (autonomy)

Analysis of the findings has revealed the impact of focusing on the students' intrinsic motivation. This has been enabled by a change of focus from education to learning [20]:

$$
\begin{array}{llll}
\text { Extrinsic } \rightarrow & \text { Curriculum } \rightarrow & \text { Passive } \rightarrow & \text { Education } \\
\text { Intrinsic } \rightarrow & \text { Curiosity } \rightarrow & \text { Active } \rightarrow & \text { Learning }
\end{array}
$$

This 'learning more by teaching less' approach can benefit from having BIM as part of the engineering students' learning objectives. Learning BIM has by this a potential to support the learning of engineering in an efficient way. This short case study does of course not give evidence for deductive interpretation in general, but it indicates that integrating BIM within the engineering curriculum can create motivated students and increase the total learning.

\section{REFERENCES}

[1] McGraw-Hill Construction, The business value of BIM in North America: multi-year trend analysis and user ratings (2007-2012). Smart Market Report, Bedford, 2012.

[2] McGough, D., Ahmed, A. \& Austin, S., Integration of BIM in higher education: case study of the adoption of BIM into Coventry university's Department of civil engineering, architecture and Building. Architecture and Building, Sustainable Building and Construction Conference SB13, Coventry University, London, 2013.

[3] Barison, M.B. \& Santos, E.T., BIM teaching strategies: an overview of the current approaches. Proceedings of ICCCBE 2010 International Conference on Computing in Civil and Building Engineering, Nottingham, 2010.

[4] Kocaturk, T. \& Kiviniemi, A., Challenges of integrating BIM in architectural education. Building Information Modelling, 2, pp. 465-473, 2013.

[5] Van Dijk, L., Van Der Berg, G. \& Van Keulen, H., Interactive lectures in engineering education. European Journal of Engineering Education, 26(1), pp. 15-28, 2001. https://doi.org/10.1080/03043790123124

[6] Kolb, D.A., Experiential learning as the science of learning and development. Prentice Hall: Englewood Cliffs, NJ, 1984.

[7] McKinney, K., Active learning. Center for Teaching, Learning, and Technology, 2010, available at: www.cat.ilstu.edu/additional/tips/newActive.php. (accessed 20 March, 2017).

[8] Blumenfeld, P.C., Soloway, E., Marx, R., Krajcik, J., Guzdial, M. \& Palincsar, A., Motivating project-based learning: sustaining the doing, supporting the learning. Educational Psychologist, 26(3-4), pp. 369-398, 1991. https://doi.org/10.1207/s15326985ep2603\&4_8

[9] Bull, G.R., Constructivism and active learning. USMA, Westpoint, NY, 2009.

[10] Barbe, W., Swassing, R. \& Milone, M., Teaching through modality strengths: concepts and practices. Zaner-Bloser: Columbus, OH, 1979. 
[11] Prince, M., Does active learning work? A review of the research. Journal of Engineering Education, 93(3), pp. 223-231. 2004. https://doi.org/10.1002/j.2168-9830.2004.tb00809.x

[12] Biggs, J.B., Teaching for quality learning at university: What the student does. McGrawHill Education: UK., 2011.

[13] Ryan, R.M. \& Deci, E.L., Self-determination theory and the facilitation of intrinsic motivation, social development, and well-being. American Psychologist, 55(1), pp. 68-78, 2000. https://doi.org/10.1037//0003-066x.55.1.68

[14] Deci, E.L., Koestner, R. \& Ryan, R.M., A meta-analytic review of experiments examining the effects of extrinsic rewards on intrinsic motivation. American Psychological Association, 125, pp. 627-668, 1999. https://doi.org/10.1037//0033-2909.125.6.627

[15] Machemer, P.L. \& Crawford, P., Student perceptions of active learning in a large crossdisciplinary classroom. Active Learning in Higher Education, 8(1), pp. 9-30, 2007. https://doi.org/10.1177/1469787407074008

[16] Underwood, J., Khosrowshahi, F., Pittard, S., Greenwood, D. \& Platts, T., Embedding Building Information Modelling (BIM) within the taught curriculum. BIM Academic Forum: York, 2013.

[17] Tafarodi, R.W. \& Swann, W.B. Jr, Self-linking and self-competence as dimensions of global self-esteem: initial validation of a measure. Journal of Personality Assessment, 65(2), pp. 322-342, 1995. https://doi.org/10.1207/s15327752jpa6502_8

[18] Huxham, M., Learning in lectures: Do 'interactive windows' help? Active Learning in Higher Education, 6(1), pp. 17-31, 2005. https://doi.org/10.1177/1469787405049943

[19] Deci, E.L. \& Ryan, R.M., The" what" and" why" of goal pursuits: Human needs and the self-determination of behavior. Psychological Inquiry, 11(4), pp. 227-268, 2000. https://doi.org/10.1207/s15327965pli1104_01

[20] Holmen, M., Education vs. learning. Bibblio.org, available at: https://medium.com/thegraph/education-vs-learning-9f0d0d5696b5\#.go1ddsoz0. (Accessed 20 March 2017). 